\title{
Cloning, Codon Optimization, and Expression of Yersinia intermedia Phytase Gene in E. coli
}

\author{
Maryam Mirzaei ${ }^{1}$, Behnaz Saffar ${ }^{2 *}$, Behzad Shareghi ${ }^{1}$ \\ ${ }^{1}$ Department of Biology, Faculty of Science, Shahrekord University, Shahrekord, Iran \\ ${ }^{2}$ Department of Genetics, Faculty of Sciences, Shahrekord University, Shahrekord, Iran \\ ${ }^{*}$ Corresponding author: Behnaz Saffar, Department of Genetics, Faculty of Science, Shahrekord University, Shahrekord, Iran. Tel/ Fax: +98-38342324419, \\ E-mail: saffar_b@sci.sku.ac.ir
}

Received: December 03, 2015; Revised: January 16, 2016; Accepted: February 24, 2016

Background: Phytate is an anti-nutritional factor in plants, which catches the most phosphorus contents and some vital minerals. Therefore, Phytase is added mainly as an additive to the monogastric animals' foods to hydrolyze phytate and increase absorption of phosphorus.

Objectives: $Y$. intermedia phytase is a new phytase with special characteristics such as high specific activity, $\mathrm{pH}$ stability, and thermostability. Our aim was to clone, express, and characterizea codon optimized Y. intermedia phytase gene in E. coli.

Materials and Methods: The $Y$. intermedia phytase gene was optimized according to the codon usage in $E$. coli. The sequence was synthesized and sub-cloned in pET-22b (+) vector and transformed into E. coli B121 (DE3). The protein was expressed in the presence of IPTG at a final concentration of $1 \mathrm{mM}$ at $30^{\circ} \mathrm{C}$. The purification of recombinant protein was performed by $\mathrm{Ni}^{2+}$ affinity chromatography. Phytase activity and stability were determined in various $\mathrm{pH}$ and temperatures.

Results: The codon optimized $Y$. intermedia phytase gene was sub-cloned successfully.The expression was confirmed by SDS-PAGE and Western blot analysis. The recombinant enzyme (approximately $45 \mathrm{kDa}$ ) was purified. Specific activity of enzyme was $3849\left(\mathrm{U}_{\mathrm{mg}}{ }^{-1}\right)$ with optimal $\mathrm{pH} 5$ and optimal temperature of $55^{\circ} \mathrm{C}$. Thermostability $\left(80^{\circ} \mathrm{C}\right.$ for $\left.15 \mathrm{~min}\right)$ and $\mathrm{pH}$ stability (3-6) of the enzyme were 56 and more than $80 \%$, respectively.

Conclusions: The results of the expression and enzyme characterization revealed that the optimized $Y$. intermedia phytase gene has a good potential to be produced commercially andto be applied in animals' foodsindustry.

Key words: Codon optimization; Expression in E. coli; Rare codons; Y. intermedia phytase

\section{Background}

Most of entire phosphorus of plants and oil seeds exist in the form of phytic acid (myo-inositol hexakisphosphate; phytate) (1). Phytate is an anti-nutritional factor with a negative side effect of binding with phosphorus, which in turn chelates some bioessential metal ions $\left(\mathrm{Zn}^{2+}, \mathrm{Ca}^{2+}, \mathrm{Cu}^{2+}, \mathrm{Fe}^{2+}\right.$, and $\left.\mathrm{Mn}^{2+}\right)$, influencing their bioavailability by forming (phytate-metal ions, phytate-phosphorus, and phytate-proteins) insoluble complexes (2). Phytase is an enzyme that hydrolyzes phytic acid into inositol and phosphorus and decreases metal ions chelation (3). Monogastric and agastric animals such as fish and chicken as well as human beings have no or very low amounts of phytase (4). Thus, to improve thequality of foods, phosphate should be added into animals' foods as a supplement (5). Obviously it is very expensive and causes environmental pollution and the phenomena of eutrophication on the water surface by excretion of the insoluble phosphorus-phytate complex into the environment, consequently wasting this vital nutrition factor (6). Due to these problems, the best option to increase the amount of phosphorus, metal ions, and protein bioavailability is to add phytase to fish and poultry food (7).

Phytases are classified into 3 groups: 1 . Histidine acid phosphatase (HAP) phytase, 2. $\beta$-propeller phytase (BPP), and 3. Purple acid phosphatase phytase (PAP) (8). Phytases are found in many plants, animals, and microorganisms, but the majority of commercial 
phytases have microbial sources, which mostly belong to HAPs (9). The extraction of wild type phytase yields little amounts of phytases; thereby,to have higher amounts, recombinant phytase should be used (10). As a commercial additive, a recombinant phytase, which is applied in the food industryshould have some special characteristics. It should be thermostable to tolerate temperature rising during digestion processes, stable on an extensive $\mathrm{pH}$ range for being active in different parts of a gastrointestinal system, and resistant to proteases (2).

Codon optimization is a critical way to produce recombinant proteins and have higher expressions. It is based on changing codons of special amino acids in the given gene, which are rare in the relative host microorganism gene, without altering the related amino acid. Codon optimization brings about some benefits: 1 . adapting the frequency of codon in two sources and host microorganisms, 2 . decreasing the repeated codons, and 3. eliminating the stop codons (11).

Many phytases from different sources such as Aspergillus ficcum (13), Bacillus sp. DS11(14), Yersinia intermedia (15), Klebsiella sp. ASR1(9), E. coli and Aspergillus niger (7) have been cloned and purified, using different hosts up to now. Among them, $Y$. intermedia, phytase has high specific activity and several advantages such as, stability, at low $\mathrm{pH}$ and high temperature that are necessary for using phytase as a food supplement. The $Y$. intermedia phytase gene, appA (APPA: a new phytase with special characteristics belonging to HAP phytases), has been overexpressed in Pichia pastoris and had high levels of expression (15).

\section{Objectives}

The purpose of this study was the overexpression of, appA in E. coli as a suitable host. Further to define the activity and stability of recombinant phyase (rAPPA) under various $\mathrm{pH}$ and temperature conditions. To the best of our knowledge, this research is the first report of the recombinant phytase production with unique features by codon optimization strategy in $E$. coli.

\section{Materials and Methods}

\subsection{Strains, Plasmids and Media}

E. coli DH5 $\alpha$ and E. coli BL21 (DE3) F-ompT hsdsB(r-Bm-) gal dcm, were used as the hosts for cloning and protein expression. pGH and pET-22b $(+)$ (Invitrogen, USA) plasmids were employed for appA cloning and expression, respectively. Luria-Bertani
(LB) agar medium (10 g.L-1 Trypoton, 5 g.L-1 Yeast Extract, 10 g.L-1 $\mathrm{NaCl}$, and Agar 16 g.L.-1) was prepared for E. coli growth. Molecular biology techniques were carried out according to the standard protocols (16).

\subsection{Codon Optimization and Sub Cloning}

The sequence of Yersinia intermedia (strain H-27) phytase gene $(a p p A)$ was obtained from GenBank (Embl: ABI95370.1). Detection of rare codons and optimization of sequence were performed by two web servers:optimizer (http://www.genoms.uvr.es) and $E$. coli rare codon analyzer2 (http://www.faculty.ucr.edu). The Gene script web server (http://www.gene script.com) was used to evaluate of designed sequence by Codon Adaptation Index (CAI). The sequence of codon optimized phytase gene (1280 bp) was synthesized chemically by Nedayfan Company, cloned in pGH vector as cloning vector, and transformed into competent cells (E. coli DH5 $\alpha$ ). The competent cells were prepared via $\mathrm{CaCl}_{2}$ method. Transformation was performed by the heat shock method, and recombinant cells were cultivated on LB agar medium containing ampicillin. Plasmid extraction was carried out through alkaline lysis method. The pGH plasmid was digested by NcoI and XhoI restriction enzymes (Thermo scientific, USA) and recovered from the gel, using Roche agarose gel DNA extraction kit, (Roche, Germany) and ligated into the same digested place pET $22 \mathrm{~b}(+)$ by T4DNA ligase (TakaRa, Japan). E. coli BL21 (DE3) competent cells were transformed by recombinant plasmid named pET22b-rAPPA.

\subsection{Protein Expression and Western-Blot Analysis}

Therecombinant cells, transformed by pET22b (+)rAPPA,were harbored in LB containing $50 \mu \mathrm{L} . \mathrm{mL}^{-1}$ ampicillin in shaking incubator at $37^{\circ} \mathrm{C}$ and $100 \mathrm{rpm}$. At $\mathrm{OD}_{600}=0.4-0.6,10 \mathrm{~mL}$ of the culture was separated and considered as uninduced. Isopropyl $\beta$-D-1-thiogalactopyranoside (1 mM IPTG) was added to the rest of the culture to induce protein expression at $30^{\circ} \mathrm{C}$. Induced samples $(10 \mathrm{~mL})$ were collected at 2,4 , and $8 \mathrm{~h}$. The cell pellets were harvested and re-suspended in TE buffer (1 mM EDTA, $10 \mathrm{mM}$ Tris base, $\mathrm{pH}$ 7.4-7.8). Sonication was performed on ice 7 times $(80 \%$ power, 0.5 pulses) for each sample (16). The supernatant as a soluble fraction was harvested by centrifugation at $12000 \times g$ for $10 \mathrm{~min}$ at $4^{\circ} \mathrm{C}$ and subjected to $10 \%$ SDSPAGE (Sodium dodecyl sulfate polyacrylamide gel electrophoresis). For Western blot analysis, proteins separated via SDS-PAGE were transferred to 
polyvinyl difluoride (PVDF) membrane by transfer buffer (25 mMTris, $192 \mathrm{mM}$ Glycine, and 20\% methanol). The membrane was incubated in blocking solution (5\% skim milk) for $2 \mathrm{~h}$. Mouse anti-(His) 6 peroxidase antibody (1:2000) (Amersham Pharmacia Biotech, Sweden) was added and incubated for $2 \mathrm{~h}$. Tetramethylbenzidine (TMB) was usedas substrate To develop an image of protein band containing the fusion tag.

\subsection{Purification of Recombinant Enzyme and Phytase Activity Assay}

Purification occurred through $\mathrm{Ni}^{2+}$-affinity chromatography (His-Bind Quick 300 Cartridges, 70155-3, Novagen) (16). Supernatant (10 m), including recombinant protein was subjected into Ni-NTA (Nickelnitrilotriacetic acid) affinity column, which was washed by washing buffer $(100 \mathrm{mM}$ Tris- $\mathrm{HCl}, 500$ $\mathrm{mM} \mathrm{NaCl}$, and $10 \mathrm{mM}$ imidazole, $\mathrm{PH}$ 8.0) and charged with $100 \mathrm{mM} \mathrm{NiSO}$. Binding buffer $(100 \mathrm{mM}$ Tris$\mathrm{HCl} \mathrm{pH} \mathrm{8.0,} \mathrm{containing} 500 \mathrm{mM} \mathrm{NaCl}$, and $20 \mathrm{mM}$ imidazole) was used to remove contaminant proteins. The recombinant fusion proteins were eluted by elution buffer $(100 \mathrm{mM}$ Tris base, $500 \mathrm{mM} \mathrm{NaCl}, 500$ $\mathrm{mM}$ Imidazole, $\mathrm{pH}$ 8). The existence of recombinant protein was evaluated by SDS-PAGE. The purified protein was dialyzed by a dialysis membrane $(10 \mathrm{kDa}$ cutoff) for removing small peptides and changing the buffer. The concentration of protein was measured via Bradford assay (17). For Phytase activity assay, Sigma-Aldrich protocol based on colorimetric method with minor modification was employed (18). Enzyme solution $(100 \mu \mathrm{L})$ was added to $900 \mu \mathrm{L}$ substrate solution $(100 \mathrm{mM}$ magnesium sulfate, $200 \mathrm{mM}$ sodium acetate buffer, $6.82 \mathrm{mM}$ phytic acid, $\mathrm{pH} 5$ ) at $55^{\circ} \mathrm{C}$ for 30 min. The reaction stopped with $10 \%$ (w/v) trichloroacetic acid (TCA). The released phosphate was measured by spectrophotometer at $\mathrm{OD}_{660}$ following the addition of $2 \mathrm{~mL}$ Tausky-Shrr color agent (TSCR) (a solution including $1 \%(\mathrm{w} / \mathrm{v})$ ammonium molybdate, $7.2 \%(\mathrm{w} / \mathrm{v})$ ferrous sulfate solution, and $1 \%(\mathrm{v} / \mathrm{v})$ sulfuric acid solution). The activity (U) of phytase was the amount of the enzyme releasing $1 \mu \mathrm{mol}$ of phosphate per min at $55^{\circ} \mathrm{C}$.

\subsection{Characterization of $r A P P A$}

Characterizationof purified rAPPA (recombinant $Y$. intermedia phytase) in various $\mathrm{pH}$ and temperatures was assayed as previously described (18). The optimum temperature of phytase activity was assayed by in cubating $100 \mu \mathrm{L}$ enzyme with $900 \mu \mathrm{L}$ substrate solution (100 mM magnesium sulfate, $200 \mathrm{mM}$ sodium acetate buffer, $6.82 \mathrm{mM}$ phytic acid, $\mathrm{pH} 5$ ) at temperatures from 30 to $80^{\circ} \mathrm{C}$ with 10 degree intervals for $30 \mathrm{~min}$. Thermal stability of the purified rAPPA was evaluated by incubation of the recombinant enzyme at $80^{\circ} \mathrm{C}$ for $5,10,15,20,25$, and $30 \mathrm{~min}$. After heating, rAPPA activity was determined at $55^{\circ} \mathrm{C}$ and $\mathrm{pH} 5$. The optimum $\mathrm{pH}$ was measured by incubating enzyme with substrate dissolved in $100 \mathrm{mM}$ buffer solutions: sodium acetate- $\mathrm{HCl}(\mathrm{pH} 3-6)$ and Tris-acetate (pH 6-7) for $30 \mathrm{~min}$ at $55^{\circ} \mathrm{C}$. To evaluate the $\mathrm{pH}$ stability, in the absence of sub strate, the enzyme was incubated with the same buffer in the range of 3-7 for $2 \mathrm{~h}$ at $37^{\circ} \mathrm{C}$. After adding substrate, phytase activity was measured as described earlier. The results were showed by percentage relative activity. Three independent experiments were carried out.

\section{Results}

\subsection{Codon Optimization and Sub-Cloning.}

According to Gene script web server, CAI (Codon Adaptation Index) was measured to be 0.63 . The CAI lower than 0.8 would not have any chance to get valuable expression in the desired host. Accordingly, the rare codons for expression of appA in E. coli were detected. There was approximately $5 \%$ of all appA sequences, containing: $1.8 \% \mathrm{AGG}, \mathrm{CGG}$, and CGA for arginine (R), 1.1\% CCC for proline (P), 094\% CTA for leucine (L), and 1.1\% ATA for isoleucine (I). The expression level in E. coli improved by replacing rare codons and less preferential codons with more favorable codon usage in E. coli; and finally CAI was measured again to be 0.83 , which was an appropriate index of expression. After optimizing, the CFD (Codon Frequency Distribution) reached its permissible range, and the GC content had a suitable amount after and before optimizing. The appA codon optimized gene was synthesized and sub cloned into pET-22b $(+)$. In recognition of sub cloning, recombinant pET-22b $(+)$-rAPPA was digested by $X h o \mathrm{I}$ and $\mathrm{Xba \textrm {I } \text { and }} 1500 \mathrm{bp}$ (appA gene) and $5273 \mathrm{bp}$ digested pET-22b (+) fragments were observed (Figure 1). Accuracy of subcloning was confirmed by sequencing.

\subsection{Protein Expression and Western-Blotting Analysis}

The expressed recombinant protein present at the supernatant of induced culture with $1 \mathrm{mM}$ IPTG were separated on SDS-PAGE (Figure 2A). A protein band $(45 \mathrm{kDa})$ was noted that further confirmed by Western analysis (Figure 2B). Ni-NTA Purification System was 


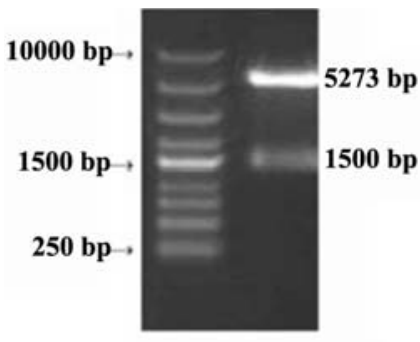

Figure 1. Agarose gel electrophoresis of double digestion of plasmid pET-22b (+)rAPPA using $\mathrm{XbaI} / \mathrm{XhoI}$ restriction enzymes. The desired $1500 \mathrm{bp}$ and $5273 \mathrm{bp}$ bands to the appA gene and the backbone of plasmid, respectively. (ladder1Kbp SMO311)

used to purify the recombinant protein carrying a $\mathrm{His}_{6}$ tag. (Figure 2C). The concentration of proteins was estimated to be about $2.8 \mathrm{mg} \cdot \mathrm{mL}^{-1}$. Furthermore, the specific activity for purified enzyme was calculated to be $3849 \pm 641{\mathrm{U} . \mathrm{mg}^{-1}}^{-1}$.

\subsection{Characterization of $r A P P A$}

The optimum $\mathrm{pH}$ of rAPPA was measured in different $\mathrm{pH}$ buffers. $100 \%$ activity was observed in $\mathrm{pH} 5$, followed by $80 \%(\mathrm{pH} 3)$ and $85 \%(\mathrm{pH} 4)$ (Figure 3A). Stability of recombinant enzyme was determined in acidic $\mathrm{pH}$ after incubation of enzyme for $2 \mathrm{~h}$ at $37^{\circ} \mathrm{C}$. Activity of rAPPA retained approximately $80 \%$ after incubation of enzyme in $\mathrm{pH}$ 3-6 (Figure 3B).

The optimum temperature of purified recombinant phytase was determined from 30 to $80^{\circ} \mathrm{C}$. The highest activity of rAPPA was obtained in $55^{\circ} \mathrm{C}$ (Figure $3 \mathrm{C}$ ). The activity of rAPPA remained approximately $66 \%$ after 10 min of being in $80^{\circ} \mathrm{C}$. Thermo stability of the enzyme at $80^{\circ} \mathrm{C}$ for $15 \mathrm{~min}$ was $56 \%$ (Figure 3D).

\section{Discussion}

Phytate is a major phosphate storage compound in seeds of higher plants, which forms complexes with multivalent metal ions such as iron, zinc, and calcium. Thus, phytase was added mainly as an additive to the mono gastric animal feed to hydrolyze phytate in order to increase absorption of phosphorus and other elements (1). For commercialization of phytase as a food supplement, the selected phytase should have some specifications such as stability on a vast $\mathrm{pH}$ range, temperature, and digestive enzymes in those animals' gastrointestinal systems. According to reports presented by Huang et al., a new phytase was found with $Y$. intermedia origin and expressed as Pichia. pastoris, showing better properties than the E. coli and A. niger phytases, as applied phytases in an animal's food (15).

E. coli in comparison Pichia is recognized to be suitable for recombinant proteins production because of its significant characteristics (19). Production of recombinant protein in $E$. coli is the quickest, easiest, and cheapest method. Therefore, E. coli was selected as host for expression of rAPPA. In this research, the theoretical and experimental results showed that the expression of codon optimized recombinant phytase was successfully performed in E. coli.

Recent studies have confirmed that rare codons can decrease expression level of recombinant proteins in E. coli. Therefore, the increase in the level of expression can be achieved by codon optimization and
A

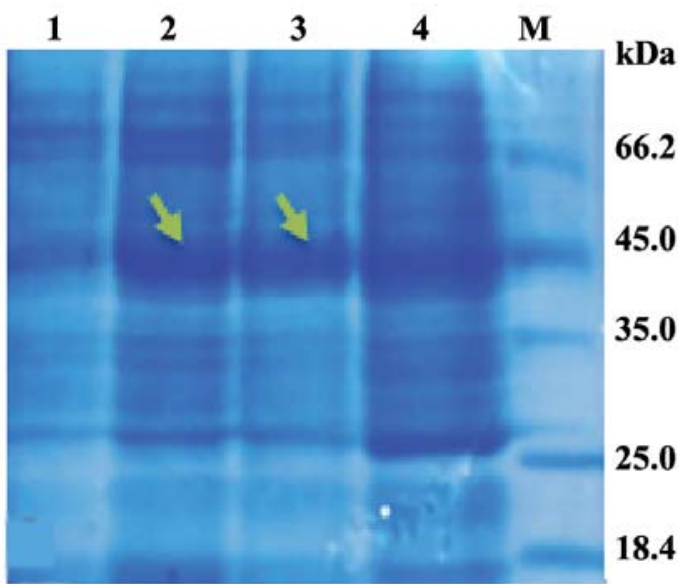

B

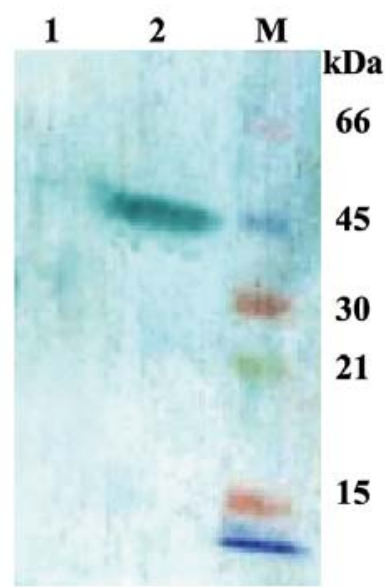

C

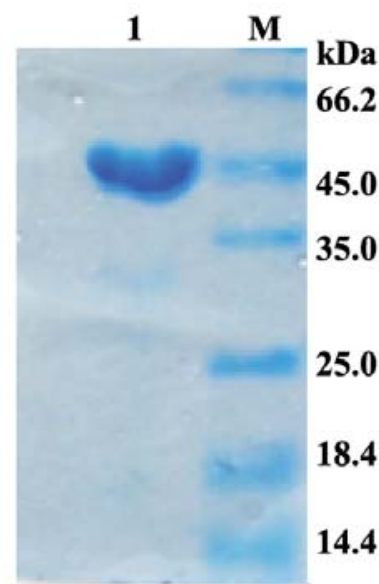

Figure 2. Analysis of protein expression and purification of recombinant phytase by SDS-PAGE and western blot analysis. A: SDS-PAGE analysis of expression pET22b-rAPPA in b121 (DE3) E. coli. Lane 1, E. coli BL21 (DE3) transformed with pET22b (+)-rAPPA before induction. Lanes (2,3 and 4), $2 \mathrm{~h}, 4 \mathrm{~h}$ and $8 \mathrm{~h}$ after induction with $1 \mathrm{mM}$ IPTG. Lane M, protein marker (SM0431). The desired bands are marked with arrows. B: Western blotting analysis of rAPPA expression. Lane 1, expression of pET22b-rAPPA, before induction. Lane 2, $4 \mathrm{~h}$ after induction. A unique significant $45 \mathrm{kDa}$ band, confirms the rAPPA expression. M: protein marker (Spectra Multicolor Broad Range). C: Recombinant protein purified by $\mathrm{Ni}^{++}$affinity chromatography. Lane M, protein marker (SM0431). Lane 1, eluted rAPPA purified 
A

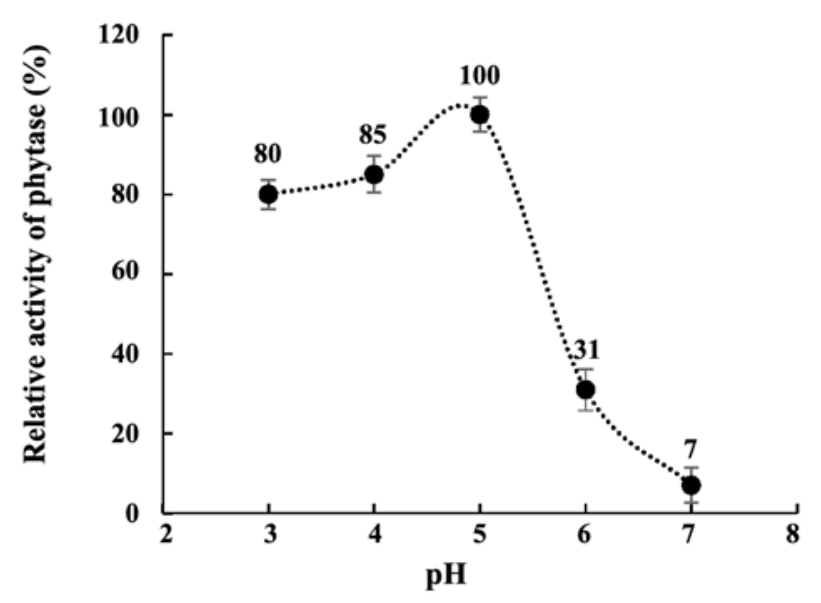

C

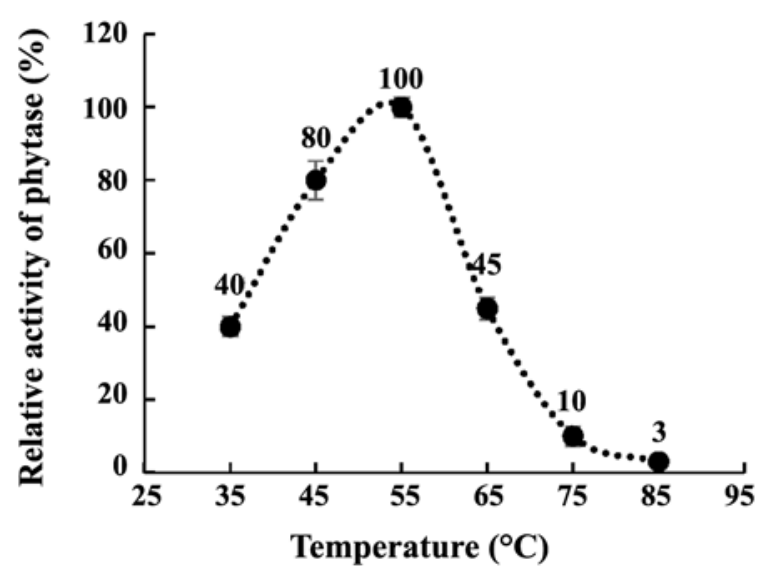

B

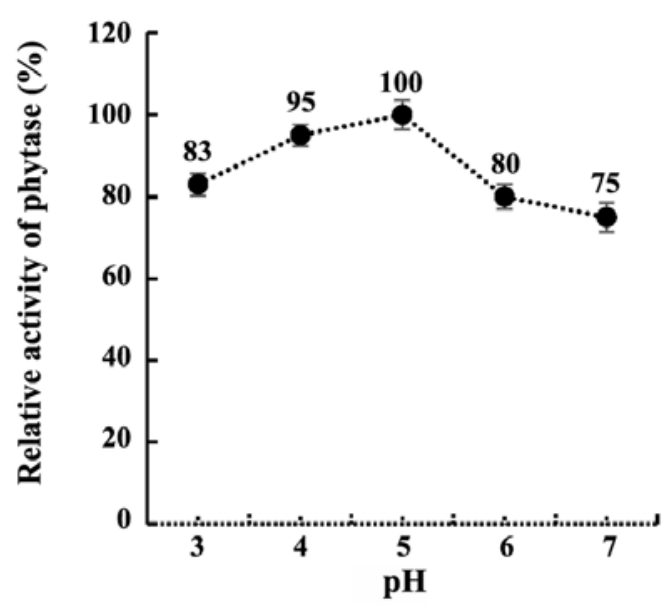

D

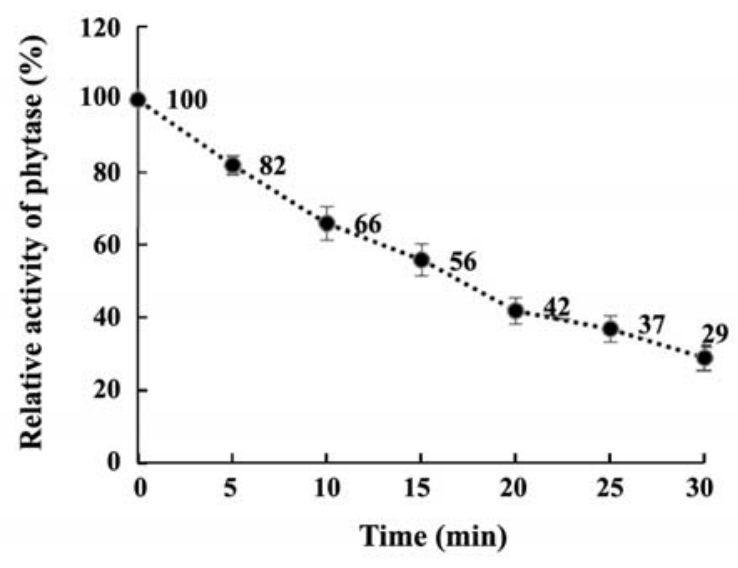

Figure 3. Temperature and $\mathrm{pH}$ profiles of recombinant $Y$. intermedia phytase (rAPPA) expressed in E. coli. A: Relative activity of rAPPA in various $\mathrm{pH}$ buffers, the optimum $\mathrm{pH}$ was $\mathrm{pH}$ 5. B: Effect of different $\mathrm{pH}$ (3-7) on the rAPPA activity, $\mathrm{pH}$ stability (3-6) of the recombinant enzyme was $80>\% \mathrm{C}$ : Relative activity of rAPPA in different temperature, the optimum temperature was obtained at $55^{\circ} \mathrm{C} \mathrm{D}: \mathrm{Heat}$ stability of rAPPA after incubating enzyme at $80^{\circ} \mathrm{C}$ for $5-30 \mathrm{~min}$, Thermostability of recombinant phytase was $56 \%$ for $15 \mathrm{~min}$ at $80^{\circ} \mathrm{C}$. $100 \%$ Activity of rAPPA was considered as the activity without any prior treatment. Three independent experiments were performed. Standard deviation was shown by error bars

replacement of rare codons with preferred codons (20). Condon optimization not only improves protein levels in expression host of choice, but also reduces sequence complexity such as secondary structures and facilitates protein folding (21). Dali et al. (2011) analyzed the $B$. subtilis phytase cloning and expression in $P$. pastoris. The cloning occurred successfully, but they had no expression because there was no harmony of codon frequencies of each amino acid in two sources and host organisms (22). According to the results, the CAI content before and after induction showed a remarkable difference. The CAI, after optimizing and changing rare codons, showed a suitable and significant range for high expression. Therefore, efficiency of rAPPA production increased by using codon-optimize dsyn- thetic gene. Recently, codon optimization offers successful high level over expression of recombinant phytase by nucleotide chemical synthesis $(23,24)$. The recombinant protein was purified by $\mathrm{Ni}^{2+}$ affinity chromatography. The results indicated that these tags has no effect on efficiency of phyase enzyme (25). The specific activity of recombinant phytase expressed in $P$. pastoris was $3960 \mathrm{U}^{\mathrm{m}} \mathrm{mg}^{-1}$ (15). A similar activity level (3849 4641 U.mg- $^{-1}$ ) was obtained once compared with the same phytase expressed in E. coli. Specific activity was high in comparison to the previous reports such as $A$. niger as a famous commercial phytase (spe\left. cific activity $100{\mathrm{U} . \mathrm{mg}^{-1}}^{-1}\right)(15,26$, and 27). In addition, similar results were observed in regards to thermo stability and $\mathrm{pH}$ stability of rAPPA expressed in E. coli 
with rAPPA in P. pastoris. Thus, E. coli be considered as a suitable host for recombinant phytase production. Finally, the activity of rAPPA in acidic $\mathrm{pH}$ and thermo stabily showed that the recombinant protein can be a good candidate as food additives. It can consequently improve the valueof animals' food in future.

\section{Conclusions}

A codon optimized Yersinia intermedia (appA) phytasegene was constructed by the pET22b (+) vector. The rAPPA expression and purification were successfully carried out in E. coli. The activity and stability of rAPPA in acidic $\mathrm{pH}$ and high temperature showed that rAPPA has a potential for commercialization and application in the animals' food industry as food additives. Despite having evaluated rAPPA activity in different $\mathrm{pH}$ and temperature, further efforts should be carried out to obtain a realistic view of recombinant phytase activity.

\section{Acknowledgments}

This study was supported fully by a grant in aid of research from Shahrekord University.

\section{Funding/Support}

This research was supported by University of Shahrkord.

\section{References}

1. Sapna JJ, Singh B. Characteristics and biotechnological applications of bacterial phytases. Process Biochem. 2016;51: 159169. DOI: 10.1016/j.procbio.2015.12.004

2. Corrêa TLR, Vieira de Queiroz M, Fernandes de Araújo E. Cloning, recombinant expression and characterization of a new phytase from Penicillium chrysogenum. Microbiol Res. 2015;170:205-212. DOI: 10.1016/j.micres.2014.06.005

3. García-Mantrana I, Yebra MJ, Haros M, Monedero V. Expression of bifidobacterial phytases in Lactobacillus casei and their application in a food model of whole-grain sourdough bread. Int. J Food Microb. 2016:4:18-24. DOI: 10.1016/j.ijfoodmicro.2015.09.003

4. Tamim N, Angel R, Christman M. Influence of dietary calcium nd phytase on phytate phosphorus hydrolysis in broiler chickens. Poult Sci. 2004;83(8):1358-1367. DOI:10.1093/ps/83.8.1358

5. Schlemmer U, Frølich W, Prieto RM, Grases F. Phytate in foods and significance for humans: food sources, intake, processing, bioavailability, protective role and analysis. Mol Nutr Food Res. 2009;53(2):330-375. DOI: 10.1002/mnfr.200900099

6. Fuhrman J, Zhang H, Schroder J, Davis R, Payton M. Watersoluble phosphorus as affected by soil to extractant Ratios, extraction times, and electrolyte. Commun Soil Sci Plant Anal. 2005,36(7):925-935. DOI: 10.1081/CSS-200049482

7. Vasudevan UM, Salim SHB, Pandey A. A comparative analysis of recombinant expression and solubility screening of two phy- tases in E. coli. Food Technol Biotech. 2011;49(3):304-309.

8. Yao MZ, Zhang YH, Lu WL, Hu MQ, Wang W, Liang AH. Phytases: crystal structures, protein engineering and potential biotechnological applications. J Appl Microbiol. 2012;112(1):114.

9. Sajidan A, Farouk A, Greiner R, Jungblut P, Müller EC, Borriss R. Molecular and physiological characterisation of a 3-phytase from soil bacterium Klebsiella sp. ASR1. Appl Microbiol Biotechnol. 2004;65(1):110-118. DOI: 10.1007/s 00253-003$1530-1$

10. Lei XG, Stahl CH. Biotechnological development of effective phytases for mineral nutrition and environmental protection. Appl Microbiol Biotechnol. 2001;57(4):474-481. DOI: 10.1007/s002530100795

11. Luo H, Yao B, Yuan T, Wang Y, Shi X, Wu N, et al. Overexpression of Escherchia coli phytase with high specific activity. Sheng Wu Gong Cheng Xue Bao. 2004;20:78-84.

12. Puigbò P, Guzmán E, Romeu A, Garcia-Vallvé S. OPTIMIZER: a web server for optimizing the codon usage of DNA sequences. Nuc Acids Res. 2007;35:126-131. DOI: 10.1093/nar/gkm219

13. Li G, Zhu J, Sun J, Wu Z, Chen J, Yan J, et al. Cloning of the phytase gene phyA from Aspergillus ficuum 3.4322 and its expression in yeast. Fungal Divers. 2003;13:85-93

14. Kim YO, Lee JK, Kim HK, Yu JH, Oh TK. Cloning of the thermostable phytase gene (phy) from Bacillus sp. DS11 and its overexpression in E. coli. FEMS Microbiol Lett. 1998;162(1):185-191. DOI: 10.1111/j.1574-6968.1998.tb 12997.x

15. Huang H, Luo H, Yang, P, Meng, K, Wang, Y, Yuan, T, et al. A novel phytase with preferable characteristics from Yersinia intermedia. Biochem Biophys Res Commun. 2006;350(4): 884-889. DOI: 10.1016/j.bbrc.2006.09.118

16. Sambrook JRD. "Molecular cloning; a laboratory manual. Cold Spring Harbor Laboratory Press, Cold Spring Harbor." New York. 2001. DOI: 10.1086/428170

17. Bradford MM. A rapid and sensitive method for the quantitation of microgram quantities of protein utilizing the principle of protein-dye binding. Anal Biochem 1976;72:248-254. DOI: 10.1016/0003-2697(76)90527-3

18. Protocol of Enzymatic Assay of phytase (E.C. 3.1.3.26) 2014. Available from https://www.sigmaaldrich.com. Accessed December 25,2014

19. Weidner M, Taupp M, Hallam SJ. Expression of recombinant proteins in the methylotrophic yeast Pichia pastoris. J Vis Exp. 2010;36:1862. DOI: 10.3791/1862

20. Aghaei Sh, Saffar B, Ghaedi K, Mobini-Dehkordi M. Functional analysis of recombinant codon-optimized bovine neutrophil $\beta$ defensin. J Adv Res. 2016. DOI: 10.1016/j.jare.2015.12.003

21. Dali NSM, Nuge T, Maifiah MHM, Yusof F, Hussin ASM, Farouk AE, Salleh HM. Molecular cloning and production of recombinant phytase from Bacillus subtilis ASUIA243 in Pichia pastoris. IIUM Engi J. 2011;12(4):99-108.

22. Weidner M, Taupp M, Hallam SJ. Expression of recombinant proteins in the methylotrophic yeast Pichia pastoris. J Vis Exp. 2010;36(1862):1-5. DOI: 10.3791/1862

23. Tan H, Wu X, Xie L, Huang Z, Peng W, Gan B. Identification and characterization of a mesophilic phytase highly resilient 
to high-temperatures from a fungus-garden associated metagenome.Appl Microbiol Biotechnol. 2015;4. DOI: 10.1007/s00253-015-7097-9

24. Tan H, Wu X, Xie L, Huang Z, Gan B, Peng W. Cloning, overexpression, and characterization of a metagenome-derived phytase with optimal activity at low $\mathrm{pH}$. J Microbiol Biotechnol. 2015;25(6):930-935. DOI: 10,4014/jmb.1411.11.12

25. Dionisio G, Madsen CK, Holm PB, Welinder KG, Jørgensen M, Stoger E, Brinch-Pedersen H. Cloning and characterization of purple acid phosphatase phytases from wheat, barley, maize, and rice. Plant. Physiol. 2011;156(3):1087-1100. DOI: http://dx.doi. org/10.1104/pp.110.164756

26. Vohra A, Satyanarayana TA. Cost-effective cane molasses medium for enhanced cell-bound phytase production by Pichia anomala. J Appl Microbiol. 2004;97(3):471-476. DOI: 10.1111/j.1365-2672.2004.02327.x

27. Tran TT, Mamo G, Mattiasson B, Hatti-Kaul RA. Thermostable phytase from Bacillus sp. MD2: cloning, expression and high-level production in E. coli. Ind Microbiol Biotechnol. 2010;37(3):279-287. DOI: 0.1007/s10295-0090671-3 